\title{
STUDIES ON MATERIAL REMOVAL RATE OF AL6061 WHILE TURNING WITH COOLANT AND WITHOUT COOLANT USING TAGUCHI METHOD
}

\author{
Deepak D $\mathbf{D}^{\mathbf{1}}$, Rajendra $\mathbf{B}^{\mathbf{2}}$ \\ ${ }^{1 \text { Author }}$ Assistant Professor, Department of Mechanical and Manufacturing Engineering, Manipal Institute of \\ Technology, Manipal University, Manipal -576104, India,. nie.deepak@gmail.com \\ 2 Corresponding Author Professor, Department of Mechanical and Manufacturing Engineering, Manipal Institute of \\ Technology, Manipal University, Manipal -576104, India., rajbeedu@yahoo.co.in
}

\begin{abstract}
:
Material Removal Rate (MRR) is one of the key attribute of machining process which influences productivity. In this work the effect of various turning process parameters on MRR produced on Al6061 (as cast condition) is investigated. Also, the effect of using coolant on MRR while turning is also determined. MRR is found to increase almost linearly with increase in feed rate. Increase in depth of cut and cutting speed is found to increase the MRR by $70.66 \%$ and $16.36 \%$ respectively.
\end{abstract}

Keywords: Al6061, Material Removal Rate, Turning Process, Spindle Speed, Depth of Cut, ANOVA, Taguchi Method

\section{INTRODUCTION}

ALUMINIUM alloys are popularly used in most of the modern day applications due to its lightweight and other attractive mechanical and thermal properties. Machinability of this material possesses relative easiness compared to other metals. Machinability quantifies the machining performance, and may be defined by various criteria, such as tool life, surface finish, chip evacuation, material removal rate and machine-tool power consumption (Songmene et. al, 2011), etc. Pure aluminium possess relatively low mechanical properties, which are improved by alloying the metal with other metals such as copper, manganese, silicon, magnesium, zinc, etc. Aluminium with magnesium and silicon as alloys are commercial designated as Al 6xxx series alloys. Among aluminium alloys Al 6061 exhibits excellent mechanical properties, corrosion resistance (Xuewu Lia,2015) and weldability (Omega Research, 2002) which finds the applications in aircraft, missiles and space, ground and marine transportation, machine parts and architectural applications. Toh et. al. (2004) studied the surface integrity effects on turned 6061 and 6061-T6 aluminium alloys. Investigations on machining of 6061 aluminium alloy with Minimum Quantity of Lubricant (MQL), dry and flooded lubricant conditions were made by Sreejith (2008). Machining effects were analyzed with respect to the cutting forces, surface roughness of the machined work-piece and tool wear. It was found that MQL condition is good alternative to flooded coolant conditions. Authors concluded that properly employed MQL can replace the flooded coolant environment which is presently employed in most of the cutting/machining applications, thereby machining will be environmental friendly and improve the machinability characteristics. Mukesh Kumar et. al. (2009) studied the effect of coated carbide tool on 6061-t4 aluminium. The effects of cutting parameters such as speed, depth of cut and cutting feed rate on the surface roughness was investigated by the authors and regression model was developed. Halil Demir et al (2009) studied the effect of artificial aging on the machinability of $6061 \mathrm{Al}$ alloy as-received, solution heat treated and then aged conditions. It was found that at different aging times (at $180^{\circ} \mathrm{C}$ ) and the cutting speed significantly affected the surface roughness of the machined surface. But, cutting forces were not significantly influenced by aging and cutting speed except for solution heat treated work pieces having the lowest hardness. Optimization of cutting parameters was carried by Carmita (2013) to minimize the energy consumption in turning of AISI 6061 T6. Machine tools shows their impact on environment due to energy consumption. Higher feed rate was found to minimize energy consumption but it led to higher surface roughness. Influence of cutting parameters on cutting force and surface finish was investigated by Rao et. al. (2013). Feed rate was found to have significant influence on cutting force as well as surface roughness. Depth of cut was found to have significant influence on cutting force, but has an insignificant influence on surface roughness. Authors have also developed the optimum combination of feed rate and depth of cut to reduce power consumption as well as to achieve the better surface finish. Vinod et. al. (2014) studied the effects of tool overhang on selection of machining parameters and surface finish. Authors found that too large and very small tool overhangs results in poor surface finish. Further, optimum range of tool overhang with minimum tool vibrations was established. Recently, Richárd Horváth et. al. (2015) studied the effect of turning the aluminum with tools having different cutting edge materials and tool edges shapes on the surface roughness. Raykar et al (2015) investigated the effect of high speed turning of Al 7075 
which is a high strength aluminium alloy. The performance of coated and uncoated carbide cutting tool was also investigated at high cutting speeds. Suitable cutting parameters with appropriate cutting tool for high speed turning of Al 7075 have been suggested by the authors. Jayaraman et. al. (2014) carried out optimization of machining parameters on turning of AA 6063 T6 aluminium alloy. In most of these works, multi-response optimization is carried out by the authors using Grey Relational Analysis (GRA) to the optimize the process parameters for the responses such as surface roughness, power consumption, material removal rate and cutting time which are found to be the most important parameters in turning.

\section{MAterials AND Methods}

\subsection{Experimental Setup and Work-piece}

Figure 1 shows the experimental set up used in the present work. Experiments were conducted using CNC turning center manufactured by ACE machine tools. The cutting tool used is silicon carbide insert. The coolant used is SAE 40. The work-piece used in the present work is Auminum 6061 in as cast condition having diameter $40 \mathrm{~mm}$ and length $150 \mathrm{~mm}$.

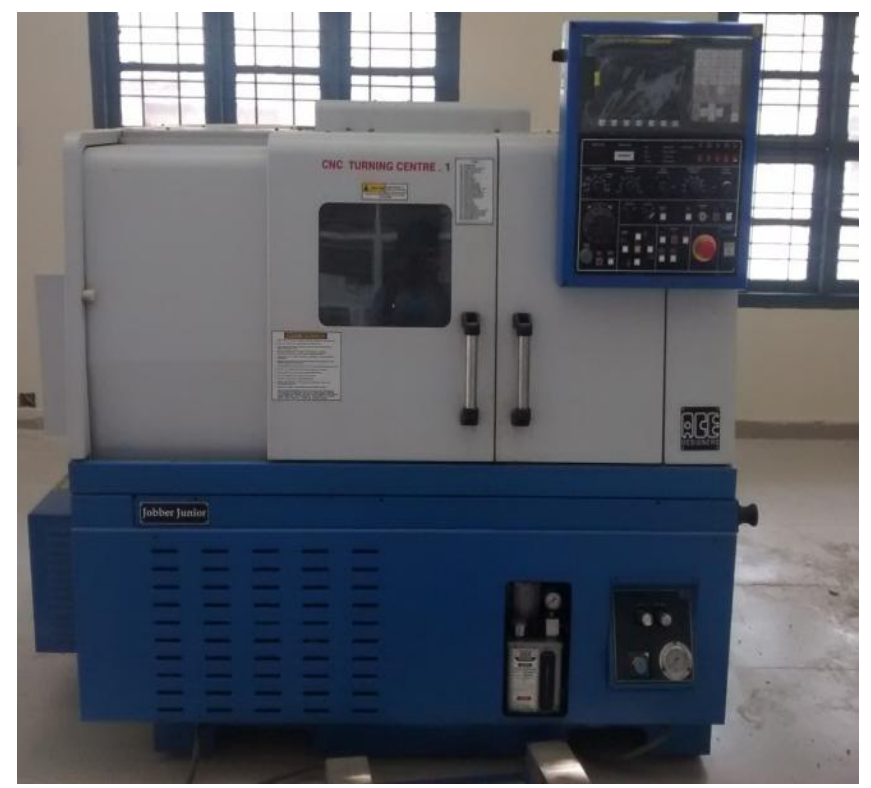

Fig. 1 Experimental set up (Deepak et. al, 2015)

2.2 Design of Experiments. The process parameters considered in the present study are shown in the Table 1. The levels of these parameters are chosen based on the pilot study conducted at various settings. Experiments were designed using Taguchi method to use the experimental resources optimally.

Table.1. Process Parameter And Their Levels

\begin{tabular}{lcccc}
\hline \multicolumn{1}{c}{ Factor/Level } & & 1 & 2 & 3 \\
\hline Cutting Speed (m/min) & A & 308 & 369 & 429 \\
Feed $(\mathrm{mm} / \mathrm{rev})$ & B & 0.05 & 0.1 & 0.15 \\
Depth of Cut $(\mathrm{mm})$ & C & 1 & 1.5 & 2 \\
\hline
\end{tabular}

Experimental design is done with $\mathrm{L}_{9}$ Taguchi orthogonal array. Experiments were conducted at various levels of the process parameters as shown in the Table 2. Each trial is conducted in two types of test conditions. In the first condition machining is carried out without using coolant (called dry machining) and in second condition machining is carried by supplying the coolant while machining. The MRR of each experimental trial is measured by volume loss method $\left(\mathrm{cm}^{3} / \mathrm{min}\right)$. Table 2 also shows the corresponding MRR values obtained in each experimental condition as mentioned in the design. The experimental results were analyzed using analysis of variance (ANOVA) to estimate the relative effect of each process parameters.

Table.2. Experimental Plan and Results

\begin{tabular}{lllllll}
\hline A & \multicolumn{1}{c}{ B } & \multicolumn{2}{c}{ C $\begin{array}{l}\text { With coolant } \\
\mathrm{MRR}_{1}\end{array}$} & $\mathrm{MRR}_{2}$ & \multicolumn{2}{c}{ Without coolant } \\
& & & $\mathrm{MRR}_{1}$ & $\mathrm{MRR}_{2}$ \\
\hline 308 & 0.05 & 1 & 8.41 & 9.25 & 7.41 & 7.41 \\
308 & 0.1 & 1.5 & 22.22 & 22.22 & 18.51 & 18.51 \\
308 & 0.15 & 2 & 44.44 & 49.99 & 44.44 & 38.88 \\
369 & 0.05 & 1.5 & 14.33 & 15.55 & 13.33 & 12.11 \\
369 & 0.1 & 2 & 35.55 & 35.50 & 31.10 & 31.10 \\
369 & 0.15 & 1 & 28.69 & 32.36 & 26.69 & 26.69 \\
429 & 0.05 & 2 & 20.74 & 20.74 & 18.14 & 15.55 \\
429 & 0.1 & 1 & 20.76 & 20.76 & 20.72 & 20.72 \\
429 & 0.15 & 1.5 & 47.62 & 51.56 & 46.62 & 46.62 \\
\hline
\end{tabular}

\section{RESULTS AND DISCUSSION}

\subsection{The Effect of Operating Parameterson MRR}

The present work investigates the effect of operating parameters such as cutting speed, feed rate and depth of cut on MRR. Figure 2 and Figure 3 shows the main effects plots of MRR obtained while machining of sample work pieces in dry mode (machining without using coolant) as well as machining by using coolant respectively. It is seen from these figures that the MRR increases with increase in the cutting speed (spindle speed). Between level 1 and level 2, the cutting speed increases by $19.80 \%$ and MRR increases by $3.40 \%$. Between level 2 and level 3, the cutting speed increases by $16.26 \%$ resulting in increasing of MRR by $12.67 \%$. At higher cutting speeds the cutting force increases which leads to easy shearing of work material. Hence, the MRR is found to increase with increase in cutting speed. However, higher cutting speeds promotes rapid tool wear.

Further, it is observed from the main effect plots shown in Figure 2 and Figure 3 that increase in feed rate leads to increase in MRR almost linearly. Between level 1 and level 2, the MRR is found to increase by $94.87 \%$ compared 62.17 $\%$ between level 2 and level 3 . This is due to the fact that at higher feed rates, thickness of the uncut chip increases resulting in increase in MRR. In addition, the effect of depth of cut on MRR is also shown in same figures. It is seen that, increase in depth of cut increases the MRR by $44.60 \%$ (level 1 to level 2) and $19.85 \%$ (level 2 to level 3). Volume of the material removal is more for the increase of depth of 
cut. Increase in depth of cut beyond the limit leads to higher thrust force which attempts to push the cutting tool radially outward thereby affects the MRR. The relative effects of chosen process parameters are determined by ANOVA shown in Table 3 and Table 4.

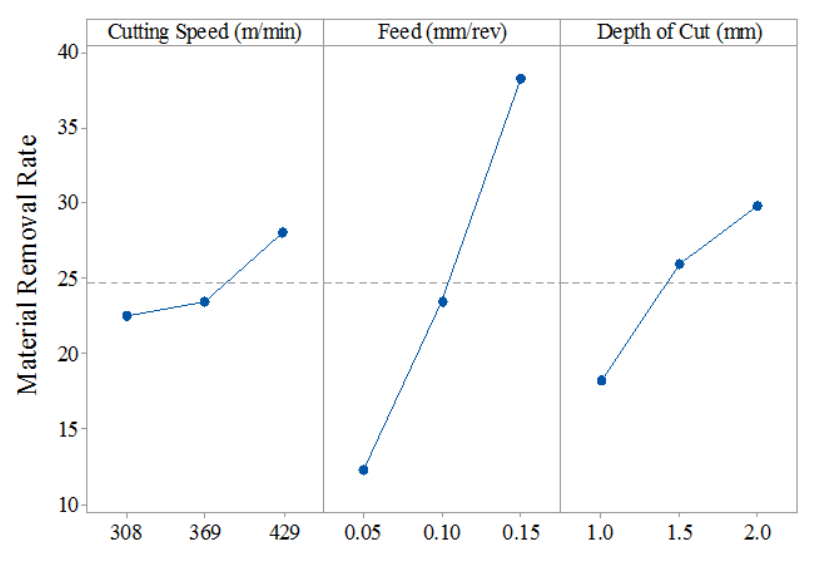

Fig. 2. Effect of operating parameters on MRR in while machining without using coolant

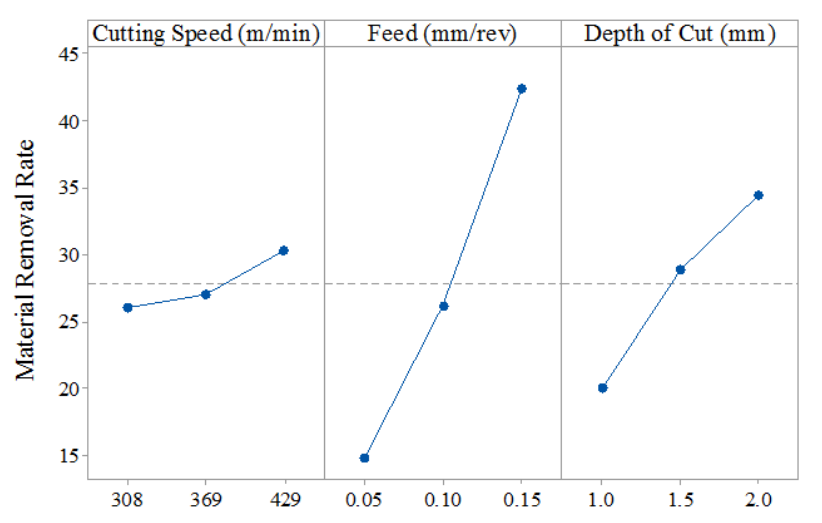

Fig. 2. Effect of operating parameters MRR when machining with coolant

Table.3. Anova For Machining Without Coolant

\begin{tabular}{|l|l|l|l|l|}
\hline Source & DF & \multicolumn{1}{|c|}{ SS } & \multicolumn{1}{c|}{ MS } & \% C \\
\hline A & 2 & 30.44 & 15.22 & 1.93 \\
\hline B & 2 & 1155.41 & 577.71 & 73.38 \\
\hline C & 2 & 318.87 & 159.44 & 20.25 \\
\hline Error & 2 & 69.91 & 34.96 & \\
\hline Total & 8 & 1574.63 & & \\
\hline
\end{tabular}

Table.4. Anova For Machining With Coolant

\begin{tabular}{|l|l|l|l|l|}
\hline Source & DF & \multicolumn{1}{|c|}{ SS } & \multicolumn{1}{c|}{ MS } & \% C \\
\hline A & 2 & 52.37 & 26.18 & 3.82 \\
\hline B & 2 & 1020.95 & 510.47 & 74.45 \\
\hline C & 2 & 208.73 & 104.36 & 15.22 \\
\hline Error & 2 & 89.33 & 44.66 & \\
\hline Total & 8 & 3.0292 & & \\
\hline
\end{tabular}

Based on the Means Square (MS) values of MRR obtained due to variations in different process parameters, the percentage contribution $(\% \mathrm{C})$ of each process parameter is determined. (MS = Sum of Square (SS) / Degree of freedom (DF)). From the ANOVA tables it can be inferred that feed rate is most influential process parameters affecting the MRR followed by depth of cut and cutting speed respectively.

\subsection{Comparative Analysis Of MRR Generated}

\section{While Machining Without Coolant And With}

\section{Coolant Supply}

The mean MRR obtained at different levels of the each process parameters in dry machining i.e., machining without supply of coolant as well as machining with coolant is calculated and is shown in Table 5. From Table 5, it is seen that higher MRR occurs at cutting speed $308 \mathrm{~m} / \mathrm{min}$ (level 3 ), feed rate $0.15 \mathrm{~mm} / \mathrm{rev}$ (level 1) and depth of cut $2 \mathrm{~mm}$ (level 3). Hence this settings for the process parameters $\left(\mathrm{A}_{3} \mathrm{~B}_{3} \mathrm{C}_{3}\right)$ can be considered as optimum settings for turning parameters to obtain the maximum material removal rate. Confirmation experiments were conducted in the above settings and results of these experiments were within the confidence interval established. It also is observed from the Table 5 that components that were machined with supply of coolant exhibited higher MRR. This is due to lesser thermal stress developed in both work-piece and the cutting tool. The percentage increase in MRR at each level of different process parameters is shown in Table 6.

Table.5. Average MRR At Deferent Levels of Process Parameters

\begin{tabular}{|l|l|l|l|l|l|l|}
\hline \multicolumn{4}{|c}{ With coolant } & \multicolumn{1}{c|}{ Without Coolant } \\
\hline Level & A & B & C & A & B & C \\
\hline 1 & 26.09 & 14.84 & 20.01 & 22.53 & 12.32 & 18.27 \\
\hline 2 & 27.00 & 26.17 & 28.92 & 23.50 & 23.44 & 25.95 \\
\hline 3 & 30.36 & 42.44 & 34.49 & 28.06 & 38.32 & 29.87 \\
\hline & 04.27 & 27.61 & 14.46 & 5.54 & 26.00 & 11.59 \\
\hline
\end{tabular}

Table.6. Percentage Improvement In MRR

\begin{tabular}{|c|c|c|c|}
\hline Level & A & B & C \\
\hline 1 & $15.80 \%$ & $20.45 \%$ & $9.47 \%$ \\
\hline 2 & $14.89 \%$ & $11.65 \%$ & $11.45 \%$ \\
\hline 3 & $8.20 \%$ & $10.75 \%$ & $15.47 \%$ \\
\hline
\end{tabular}

\section{CONCLUSION}

Following conclusions are drawn from the present experimental work.

- It is observed that the feed rate is most influential process parameters that influence MRR while turning of Aluminum 6061 followed by depth of cut and cutting speed.

- MRR is found to increase almost linearly (185\%) with increase in feed rate. Increase in depth of cut and cutting speed is found to increase the MRR by $70.66 \%$ and 16.36 $\%$ respectively.

- Machining of the work piece by the supply of coolant is 
found to produce higher material rate compared to machining without using coolant.

\section{REFERENCES}

[1]. Carmita Camposeco-Negrete, 2013, Optimization of cutting parameters for minimizing energy consumption in turning of AISI 6061 T6 using Taguchi methodology and ANOVA, Journal of Cleaner Production, Volume 53, 15 pp. 195-203

[2]. Deepak D, Rajendra B, 2015, Investigations on the surface roughness produced in turning of Al6061 (AsCast) by Taguchi method" in International Journal of Research in Engineering and Technology, Volume: 04 Issue: 08

[3]. Horváth, R., \& Drégelyi-Kiss, Á, 2015, Analysis of surface roughness of aluminium alloys fine turned: united phenomenological models and multiperformance optimization, Measurement, vol-65, pp.181-192

[4]. Halil Demir, Süleyman Gündüz, 2009, The effects of aging on machinability of 6061 aluminium alloy, Materials and Design vol 30, 1480-1483

[5]. Jayaraman, P., Kumar, L. M., 2014, Multi-response Optimization of Machining Parameters of Turning AA6063 T6 Aluminium Alloy using Grey Relational Analysis in Taguchi Method, Procedia Engineering, 97, 197-204. doi:10.1016/j.proeng.2014.12.242

[6]. Mukesh Kumar Barua, Anbuudayasankar, Measurement of surface roughness through RSM: effect of coated carbide tool on 6061-t4 aluminium, International Journal of Enterprise Network Management, Volume 4, Issue 2, DOI: 10.1504/IJENM.2010.037931

[7]. Paneerselvam, 2012, Design and analysis of experiments, PHI learning private ltd., ISBN 978-81203-4499-0

[8]. C. J. Rao, D. Nageswara Rao, P. Srihari, 2013, Influence of cutting parameters on cutting force and surface finish in turning operation, International Conference On DESIGN AND MANUFACTURING, IConDM 2013, Procedia Engineering 64, pp. 1405 1415

[9]. Raykar, S. J., D Addona, D. M., Mane, a. M. (2015). Multi-objective Optimization of High Speed Turning of Al 7075 Using Grey Relational Analysis, Procedia CIRP, 33, 293-298. doi:10.1016/j.procir.2015.06.052

[10]. P.S. Sreejith, Machining of 6061 aluminium alloy with MQL, dry and flooded lubricant conditions, 2008, Materials Letters, Volume 62, Issue 2, Pp.276-278

[11]. V. Songmene, R. Khettabi, I. Zaghbani, J. Kouam, and A. Djebara, 2011, Machining and Machinability of Aluminum Alloys, Aluminium Alloys, Theory and Applications, Tibor Kvackaj (Ed.), ISBN: 978-953307- 244-9

[12]. Vinod Mishraa, Gufran S. Khanb, K.D. Chattopadhyaya, Keshva Nanda, RamaGopal V. Sarepakaa, 2014, Effects of tool overhang on selection of machining parameters and surface finish during diamond turning, Measurement, Volume 55, Pp. 353361
[13]. Xuewu Lia, Qiaoxin Zhanga, Zheng Guo, Tian Shi, Jingui Yu, Mingkai Tang, Xingjiu Huang, 2015, Fabrication of superhydrophobic surface with improved corrosion inhibition on 6061 aluminum alloy substrate, Applied Surface Science, Volume 342, pp. 76-83 